Article

\title{
Precipitation of Pt Nanoparticles inside Ion-Track-Etched Capillaries
}

\author{
Shunya Yamamoto *, Hiroshi Koshikawa, Tomitsugu Taguchi and Tetsuya Yamaki $\mathbb{D}$ \\ Department of Advanced Functional Materials Research, National Institutes for Quantum and Radiological \\ Science and Technology (QST), Takasaki, Gunma 370-1292, Japan; koshikawa.hiroshi@qst.go.jp (H.K.); \\ taguchi.tomitsugu@qst.go.jp (T.T.); yamaki.tetsuya@qst.go.jp (T.Y.) \\ * Correspondence: yamamoto.shunya@qst.go.jp; Tel.: +81-27-346-9129
}

Received: 8 January 2020; Accepted: 4 February 2020; Published: 6 February 2020

\begin{abstract}
Ion-track-etched capillaries containing nanoparticles of precious metals (e.g., $\mathrm{Pt}, \mathrm{Au}$, and $\mathrm{Ag}$ ) can be applied to plasmonic absorber materials. The precipitation of homogeneous and highly dispersed precious metal nanoparticles inside capillaries represents a key process. Ion-track-etched capillaries (diameter: $\sim 500 \mathrm{~nm}$, length: $\sim 25 \mu \mathrm{m}$ ) were created in polyimide film by $350 \mathrm{MeV}$ Xe irradiation $\left(3 \times 10^{7} \mathrm{ions} / \mathrm{cm}^{2}\right)$ and chemical etching (using a sodium hypochlorite solution). The films with capillaries were immersed in an aqueous solution containing $0.1-10 \mathrm{mmol} / \mathrm{L} \mathrm{H}_{2} \mathrm{PtCl}_{6}$ and 0.5 $\mathrm{vol} \% \mathrm{C}_{2} \mathrm{H}_{5} \mathrm{OH}$, and then irradiated with a $2 \mathrm{MeV}$ electron beam up to a fluence of $1.4 \times 10^{16} \mathrm{e} / \mathrm{cm}^{2}$. The Pt particles inside the capillaries were characterized by scanning electron microscopy (SEM) and transmission electron microscopy (TEM). The precipitation of Pt nanoparticles and isolated aggregates inside the capillaries was confirmed by TEM. The Pt nanoparticles tended to aggregate under increasing concentrations of $\mathrm{H}_{2} \mathrm{PtCl}_{6}$ in the aqueous solution; meanwhile, no changes in nanoparticle size were noted under increasing electron beam fluence. The results suggest that the proposed method can be used to form metal nanoparticles in nanosized capillaries with a high aspect ratio.
\end{abstract}

Keywords: nanoparticles; Pt; ion irradiation

\section{Introduction}

Aligned capillaries containing precious metal nanoparticles can be applied to plasmonic absorber materials. Nanoparticles of precious metals (e.g., $\mathrm{Pt}, \mathrm{Au}$, and $\mathrm{Ag}$ ) have been widely employed as light absorbers with localized surface plasmon resonance. Plasmonic absorbers, which have the ability to convert light energy into heat energy, have been developed for solar steam generation [1-3]. By also assigning catalytic qualities to plasmonic absorbers, it would be possible to apply them to gas-reforming materials and exploit the Sun's light energy. For example, the use of Pt catalysts would allow the generation of hydrogen gas from organic chemical hydride.

The ability to form highly dispersed precious metal nanoparticles into a narrow space is essential for the fabrication of gas-reforming materials (which can convert light energy into heat energy through their plasmonic absorbers). Aligned capillaries made of flexible film can allow unidirectional gas flows and act as filters. High-aspect-ratio capillaries (diameter: several hundreds of $\mathrm{nm}$, length: several tens of $\mu \mathrm{m}$ ) containing catalytic and plasmonic nanoparticles have the following property: they remain in contact with catalytic and plasmonic nanoparticles over a period of time sufficient for the development of gas-reforming and heating reactions, respectively. Thus, aligned and high-aspect-ratio capillaries containing highly dispersed precious metal nanoparticles and made of flexible and visible-light transparent materials can be applied to develop high-performance gas-reforming materials capable of using the Sun's light energy. A key process in this context is the precipitation of homogeneous 
and highly dispersed precious metal nanoparticles inside the capillaries. Ion-track-etched capillaries created in polymer films by ion beam irradiation and chemical etching have various applications. For example, they can be used as templates for metal nanowires [4,5], for the creation of perfect blackbody sheets [6,7], and (associated to precious metal nanoparticles) to that of plasmonic absorbers. Precious metal nanoparticles can be obtained by precipitating them from a solution using ionizing radiations (e.g., high-energy electron beams, $\gamma$-rays, and ion beams) [8-10]: the penetration of an aqueous solution containing metal ions into a narrow space allows the precipitation of homogeneous and highly dispersed metal nanoparticles, without the need for heating and adding a reducing agent.

In this study, we demonstrated the creation of ion-track-etched capillaries containing $\mathrm{Pt}$ nanoparticles in polyimide film by using swift heavy ion beam irradiation and chemical etching. In addition, we investigated the influence of different $\mathrm{H}_{2} \mathrm{PtCl}_{6}$ concentrations in the aqueous solution and of the electron beam fluence on the Pt nanoparticles precipitation inside the ion-track-etched capillaries. The results indicated the formation of homogeneous $\mathrm{Pt}$ nanoparticles and isolated aggregates inside the capillaries of polyimide film. Thus, it was demonstrated that a combination of swift heavy ion beam and high energy electron beam irradiations can be used to produce capillaries containing metal nanoparticles and made of flexible polymer film.

\section{Materials and Methods}

Ion-track-etched capillaries were produced in polyimide films by ion irradiation and chemical etching. Polyimide film purchased from DU PONT-TORAY(Kapton, thickness: $25 \mu \mathrm{m}$, Tokyo, Japan) was cut into pieces of $10 \times 10 \mathrm{~cm}^{2}$; then, the film pieces were irradiated with $350 \mathrm{MeV}^{129} \mathrm{Xe}^{23+}$ ions using an azimuthally varying field (AVF) cyclotron accelerator (Sumitomo Heavy Industries, Tokyo, Japan) located at the National Institutes for Quantum and Radiological Science and Technology (QST). A vacuum chamber with a turntable-type film-carrier was pumped down to $1 \times 10^{-3} \mathrm{~Pa}$ during the ion irradiation. An ion beam of $5 \mathrm{nA}$, covering an area of $10 \times 10 \mathrm{~cm}^{2}$, irradiated the films at a fluence of $3 \times 10^{7}$ ions $/ \mathrm{cm}^{2}$. Uniform ion beam irradiations perpendicular to the film surface were conducted by using an xy-scanner system with a scanning frequency of $5 \mathrm{~Hz}$ (x-scan) and $0.5 \mathrm{~Hz}$ (y-scan). Stopping and range of ions in matter (SRIM) calculations indicated that a $350 \mathrm{MeV}$ xenon ion beam could reach a substantial penetration depth of $39 \mu \mathrm{m}$ and a linear energy transfer of 12.5 $\mathrm{MeV} / \mu \mathrm{m}$ in the polyimide films (density: $1.42 \mathrm{~g} / \mathrm{cm}^{3}$ ) [11]. Such data suggested that $350 \mathrm{MeV}$ xenon ions could completely penetrate $25-\mu \mathrm{m}$ thick polyimide films. The irradiated films, which were cut into several small pieces, were etched in a sodium hypochlorite ( $\mathrm{NaClO}$ ), (FUJIFILM Wako Pure Chemical, Osaka, Japan) aqueous solution at $60^{\circ} \mathrm{C}$ to create the capillaries. The diameter of such capillaries can be controlled by adjusting the etching time. In this particular case, the irradiated films were immersed into the solution for 10-40 min. After the chemical etching process, the polyimide film samples were washed with purified water and air-dried.

The electrical conductivity of the samples was enhanced for subsequent scanning electron microscope (SEM), (JEOL, Tokyo, Japan) and transmission electron microscope (TEM), (JEOL, Tokyo, Japan) observations by heating (i.e., carbonizing) them in the presence of $\mathrm{N}_{2}$ for $3 \mathrm{~h}$ at $530{ }^{\circ} \mathrm{C}$. Additionally, platinum nanoparticles were prepared from a solution by precipitation, using a high-energy electron beam. The heat-treated polyimide films were immersed in an aqueous solution containing 0.1-10 mmol/L hexachloroplatinic acid hexahydrate $\left(\mathrm{H}_{2} \mathrm{PtCl}_{6}\right)$, (Kojima Chemicals, Saitama, Japan) and $0.5 \mathrm{vol} \%$ ethanol $\left(\mathrm{C}_{2} \mathrm{H}_{5} \mathrm{OH}\right)$, (FUJIFILM Wako Pure Chemical, Osaka, Japan), and then irradiated with a $2 \mathrm{MeV}$ electron beam using a 2-MV electron accelerator (Nissin Electric, Kyoto, Japan) at located at the QST. The electron beam irradiation of films in an aqueous solution requires the passage of a high-energy electron beam through the films. The semiempirical depth-dose code EDMULT, indicated that a $2 \mathrm{MeV}$ electron beam was sufficiently energetic to penetrate $6.7 \mathrm{~mm}$ of polyimide and $8.7 \mathrm{~mm}$ of water. The film samples were located at the bottom of a glass vessel that was filled with an aqueous solution up to $5 \mathrm{~mm}$ from its bottom, and then irradiated with an electron beam of $4.6 \times 10^{11} \mathrm{e} / \mathrm{cm}^{2} \cdot \mathrm{s}$. Homogeneous electron beam irradiations were conducted on the samples using a 
scanning electron beam of $120 \times 5 \mathrm{~cm}^{2}$, which was irradiated perpendicularly to the samples' surface. The morphology of the ion-track-etched capillaries and of the Pt particles inside these capillaries were characterized by SEM (JSM-6700F, JEOL) and TEM (JEM-2100F, JEOL); in particular, cross-sectional TEM samples of the Pt particles were prepared with an ion slicer (IB-090600CIS, JEOL).

\section{Results and Dissociation}

The diameter of the ion-track-etched capillaries was controlled by ion-irradiating the polyimide films over different chemical etching times (10 $\mathrm{min}, 20 \mathrm{~min}$, and $40 \mathrm{~min}$ ). Figure 1 shows the SEM images of some ion-track-etched capillaries in polyimide films obtained by applying $350 \mathrm{MeV}$ xenon ion irradiation $\left(3 \times 10^{7}\right.$ ions $\left./ \mathrm{cm}^{2}\right)$ and different chemical etching times. The films were coated with $\mathrm{Au}$ by sputtering to avoid charge-up on the surface. Cylindrical holes were formed on the films and their diameter was enlarged by increasing the etching time. The SEM images demonstrated that a chemical etching time of 10-40 min enabled the formation of capillaries with diameters of 300-800 $\mathrm{nm}$. Figure 2 shows a cross-sectional SEM image of ion-track-etched capillaries created in one of the heat-treated polyimide films after an etching time of $20 \mathrm{~min}$ : the capillaries presented a diameter of $\sim 500 \mathrm{~nm}$ and were aligned perpendicularly to the film surface, suggesting that the capillaries formed along the trajectory of a single Xe ion incident beam perpendicular to the film. Furthermore, the SEM observations revealed that the capillaries penetrated the films. To ease the SEM observations (considering their conventional magnification and the preparation of cross-sectional samples), we let the Pt nanoparticles precipitate through ion-track-etched capillaries with diameters of $\sim 500 \mathrm{~nm}$.
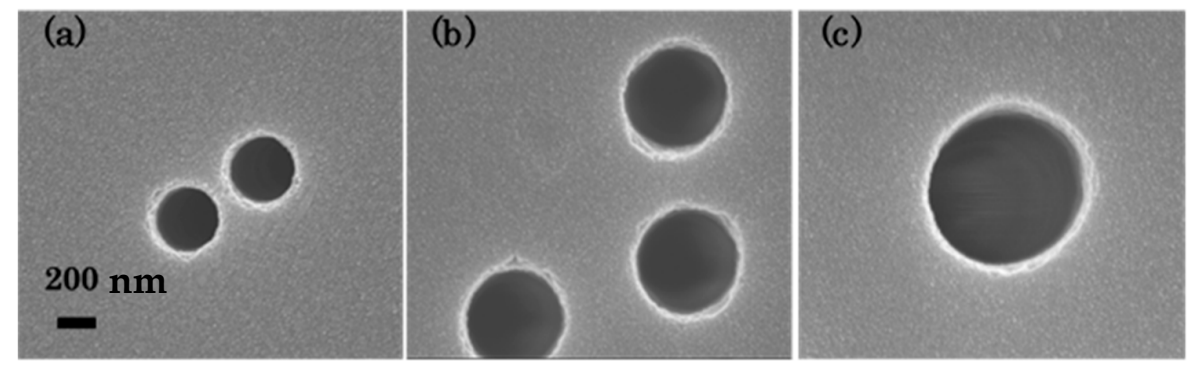

Figure 1. Top-view SEM images of ion-track-etched capillaries in the polyimide films produced using different chemical etching times: (a) $10 \mathrm{~min}$, (b) $20 \mathrm{~min}$, and (c) $40 \mathrm{~min}$.

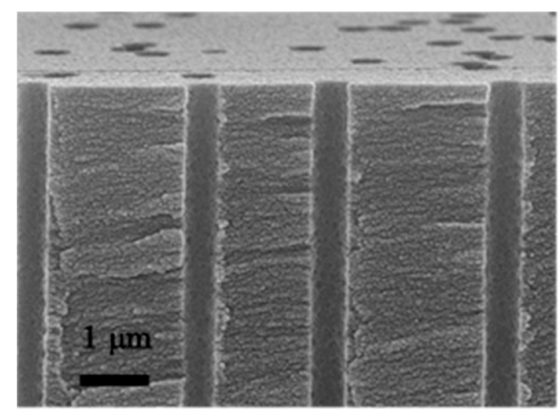

Figure 2. Cross-sectional SEM image of ion-track-etched capillaries created in a heat-treated polyimide film after an etching time of $20 \mathrm{~min}$.

To investigate the influence of $\mathrm{H}_{2} \mathrm{PtCl}_{6}$ on the precipitation of Pt nanoparticles into the capillaries, we prepared film samples under different $\mathrm{H}_{2} \mathrm{PtCl}_{6}$ concentrations $(0.1,0.5,10 \mathrm{mmol} / \mathrm{L})$ and observed them by SEM. Such observations confirmed the precipitation of Pt nanoparticles on the film surface and inside the capillaries. Figure 3 shows a few cross-sectional SEM images of capillaries in films prepared under different $\mathrm{H}_{2} \mathrm{PtCl}_{6}$ concentrations: (a) $0.1 \mathrm{mmol} / \mathrm{L}$, (b) $0.5 \mathrm{mmol} / \mathrm{L}$, and (c) $10 \mathrm{mmol} / \mathrm{L}$. The film samples were irradiated with an electron beam at a fluence of $1.4 \times 10^{16} \mathrm{e} / \mathrm{cm}^{2}$. In the sample prepared using $0.1 \mathrm{mmol} / \mathrm{L} \mathrm{H}_{2} \mathrm{PtCl}_{6}$, the Pt nanoparticles (size: $<5 \mathrm{~nm}$ ) with isolated aggregates were distributed 
on the wall of the ion-track-etched capillaries. Under increasing $\mathrm{H}_{2} \mathrm{PtCl}_{6}$ concentration, the number density of the Pt nanoparticles with isolated aggregates increased and the diameter of aggregates along the major axis direction reached several tens of $\mathrm{nm}$ (Figure $3 \mathrm{~b}$ ). The sample prepared using 10 $\mathrm{mmol} / \mathrm{L}$ (Figure 3c) presented Pt aggregates with inhomogeneous shape and size on the wall of the capillaries. The size of these Pt aggregates reached $\sim 100 \mathrm{~nm}$, suggesting that their size increased with the concentration of $\mathrm{H}_{2} \mathrm{PtCl}_{6}$ in the aqueous solution. The influence of different electron beam fluences $\left(1.4 \times 10^{15} \mathrm{e} / \mathrm{cm}^{2}, 5.6 \times 10^{15} \mathrm{e} / \mathrm{cm}^{2}\right.$, and $\left.1.4 \times 10^{16} \mathrm{e} / \mathrm{cm}^{2}\right)$ on the precipitation of the Pt nanoparticles into the capillaries using $0.5 \mathrm{mmol} / \mathrm{L} \mathrm{H}_{2} \mathrm{PtCl}_{6}$ was also investigated: the SEM observations revealed that the size of the $\mathrm{Pt}$ nanoparticles, the number density and size of the Pt aggregates did not change under increasing electron beam fluence. Formation of Pt nanoparticles seems to be finished due to depletion of the precursor below a fluence of $1.4 \times 10^{15} \mathrm{e} / \mathrm{cm}^{2}$. Overall, we verified that it is possible to induce the formation of homogenous $\mathrm{Pt}$ nanoparticles into ion-track-etched capillaries by electron beam irradiation reduction and controlling the concentration of $\mathrm{H}_{2} \mathrm{PtCl}_{6}$ in the aqueous solution.

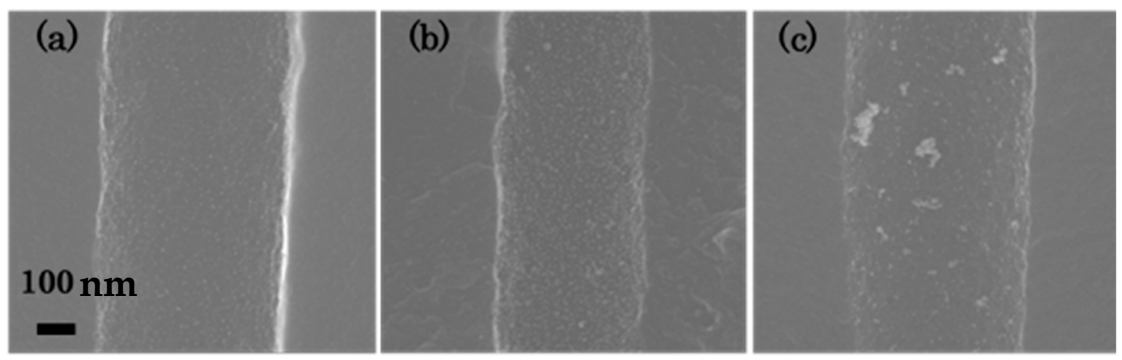

Figure 3. Cross-sectional SEM images of capillaries created under different $\mathrm{H}_{2} \mathrm{PtCl}_{6}$ concentrations: (a) $0.1 \mathrm{mmol} / \mathrm{L}$, (b) $0.5 \mathrm{mmol} / \mathrm{L}$, and (c) $10 \mathrm{mmol} / \mathrm{L}$.

Figure 4a shows two cross-sectional TEM images of precipitated Pt nanoparticles located on the wall of an ion-track-etched capillary, which was formed in a heat-treated polyimide film after an etching time of $20 \mathrm{~min}$. The $\mathrm{Pt}$ nanoparticles with isolated aggregates, prepared under a $\mathrm{H}_{2} \mathrm{PtCl}_{6}$ concentration of $0.5 \mathrm{mmol} / \mathrm{L}$ and an electron beam fluence of $1.4 \times 10^{16} \mathrm{e} / \mathrm{cm}^{2}$ were distributed homogeneously inside the ion-track-etched capillary. The size of the Pt nanoparticles (i.e., their diameter in the major axis direction) was measured based on high-magnification TEM images. The isolated aggregates were composed of Pt nanoparticles with sizes $<5 \mathrm{~nm}$ (Figure $4 \mathrm{~b}$ ). The high-resolution TEM observations (i.e., lattice images) revealed that the Pt nanoparticles had a crystalline structure; moreover, those with sizes between 1.9-5.1 nm were connected to each other. Overall, the TEM observations confirmed the formation of Pt nanoparticles with isolated aggregates into ion-track-etched capillaries in heat-treated polyimide films.
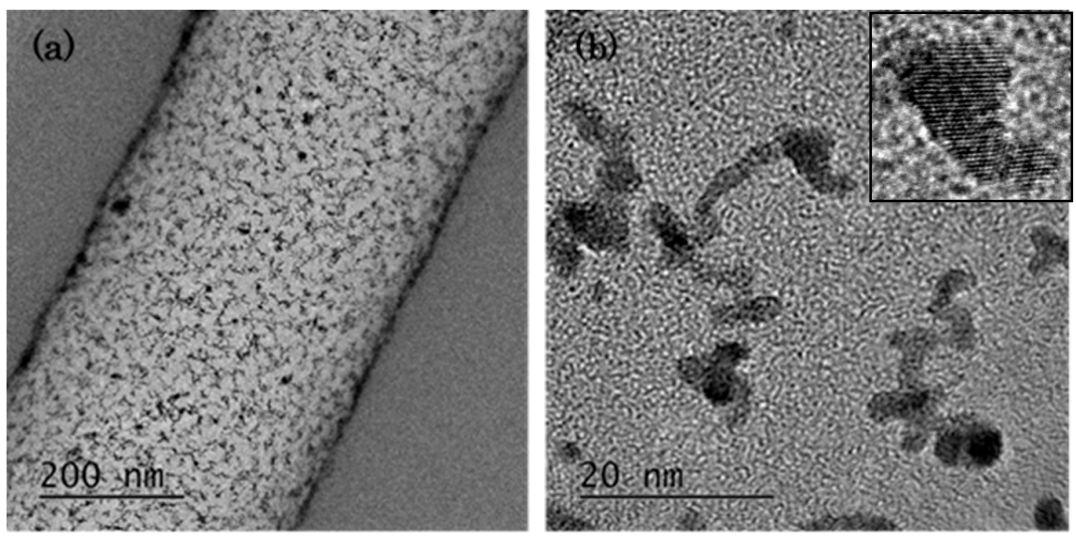

Figure 4. (a) Low- and (b) high-magnification cross-sectional TEM images of Pt nanoparticles precipitated into an ion-track-etched capillary in a heat-treated polyimide film. 
The practical application of $\mathrm{Pt}$ nanoparticles in ion-track-etched capillaries requires the precipitation of $\mathrm{Pt}$ nanoparticles in without heat-treated polyimide films by this method. The precipitation of such nanoparticles was confirmed by using $\mathrm{H}_{2} \mathrm{PtCl}_{6}$ at a concentration of $0.5 \mathrm{mmol} / \mathrm{L}$ and an electron beam fluence of $1.4 \times 10^{16} \mathrm{e} / \mathrm{cm}^{2}$. The cross-sectional TEM image in Figure 5 shows the presence of Pt nanoparticles on the wall of an ion-track-etched capillary in one of the polyimide films. Overall, our results indicate that the proposed electron beam irradiation reduction method can be used to create nanosized capillaries containing Pt nanoparticles in polyimide films.

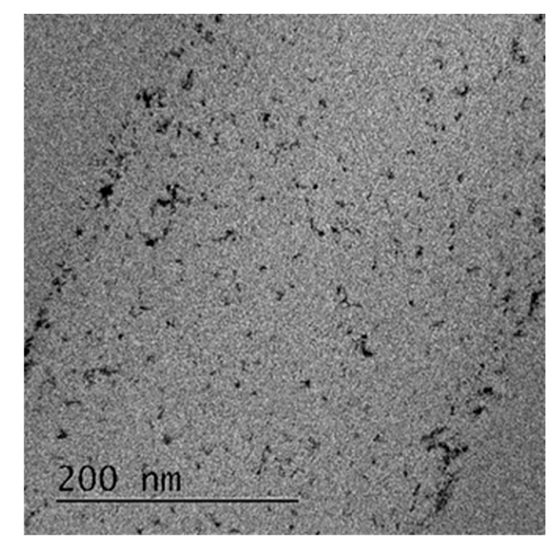

Figure 5. Cross-sectional TEM image of precipitated Pt nanoparticles into an ion-track-etched capillary in one of the polyimide films.

\section{Conclusions}

This study demonstrated a facile approach to the preparation of ion-track-etched capillaries containing Pt nanoparticles in polyimide films. First, swift heavy ion beam irradiation and chemical etching were used to prepare nanosized capillaries with a high aspect ratio in polyimide films. Then, homogeneous and highly dispersed Pt nanoparticles were precipitated inside the ion-track-etched capillaries by electron beam irradiation reduction. In conclusion, we demonstrated that a combination of ion and electron beam irradiation techniques can be applied to the production of capillaries containing metal nanoparticles in flexible polymer films.

Author Contributions: Conceptualization, S.Y.; methodology, S.Y. and H.K.; investigation, S.Y. and T.T.; writing —original draft preparation, S.Y.; writing—review and editing, S.Y. and H.K.; supervision, T.Y.; project administration, T.Y. All authors have read and agreed to the published version of the manuscript.

Funding: This work was financially supported by JSPS KAKENHI Grant Number 18K04739.

Acknowledgments: The authors thank Chihiro Suzuki for her help with the TEM observations.

Conflicts of Interest: The authors declare no conflict of interest.

\section{References}

1. Zhou, L.; Tan, Y.; Ji, D.; Zhu, B.; Zhang, P.; Xu, J.; Gan, Q.; Yu, Z.; Zhu, J. Self-assembly of highly efficient, broadband plasmonic absorbers for solar steam generation. Sci. Adv. 2016, 2, e150127. [CrossRef] [PubMed]

2. Liu, F.; Lai, Y.; Zhao, B.; Bradley, R.; Wu, W. Photothermal materials for efficient solar powered steam generation. Front. Chem. Sci. Eng. 2019, 13, 636. [CrossRef]

3. Kosuga, A.; Yamamoto, Y.; Miyai, M.; Nishimura, Y.; Hidaka, S.; Yamamoto, K.; Tanaka, S.; Yamamoto, Y.; Tokonami, S.; Iida, T. A high performance photothermal film with spherical shell-type metallic nanocomposites for solar thermoelectric conversion. Nanoscale 2015, 7, 7580-7584. [CrossRef] [PubMed]

4. Koshikawa, H.; Usui, H.; Maekawa, Y. Thermally stable and anisotropically conducting membranes consisting of sub-micron copper wires in polyimide ion track membranes. J. Membr. Sci. 2009, 327, 182-187. [CrossRef]

5. Apel, P. Track etching technique in membrane technology. Radiat. Meas. 2001, 34, 559-566. [CrossRef] 
6. Amemiya, K.; Koshikawa, H.; Yamaki, T.; Maekawa, Y.; Shitomi, H.; Numata, T.; Kinoshita, K.; Tanabe, M.; Fukuda, D. Fabrication of hard-coated optical absorbers with microstructured surfaces using etched ion tracks: Toward broadband ultra-low reflectance. Nucl. Instrum. Methods Phys. Res. Sect. B 2015, 356-357, 154-159. [CrossRef]

7. Amemiya, K.; Koshikawa, H.; Imbe, M.; Yamaki, T.; Shitomi, H. Perfect blackbody sheets from nano-precision microtextured elastomers for light and thermal radiation management. J. Mater. Chem. C 2019, 7, 5418-5425. [CrossRef]

8. Belloni, J. Nucleation, growth and properties of nanoclusters studied by radiation chemistry: Application to catalysis. Catal. Today 2006, 113, 141-156. [CrossRef]

9. Ohkubo, Y.; Kageyama, S.; Seino, S.; Nakagawa, T.; Kugai, J.; Ueno, K.; Yamamoto, T.A. Mass production of highly loaded and highly dispersed $\mathrm{PtRu} / \mathrm{C}$ catalysts for methanol oxidation using an electron-beam irradiation reduction method. J. Exp. Nanosci. 2016, 11-12, 123-137. [CrossRef]

10. Saykar, N.G.; Phatangare, A.; Banerjee, I.; Bhoraskar, V.N.; Ray, A.K.; Mahapatra, S.K. Electron beam induced synthesis of Ru-rGO and its super capacitive behavior. 2D Mater. 2019, 6, 045030. [CrossRef]

11. Ziegler, J.F.; Ziegler, M.D.; Biersack, J.P. SRIM-The stopping and range of ions in matter. Nucl. Instrum. Methods Phys. Res. Sect. B 2010, 268, 1818-1823. [CrossRef]

(C) 2020 by the authors. Licensee MDPI, Basel, Switzerland. This article is an open access article distributed under the terms and conditions of the Creative Commons Attribution (CC BY) license (http://creativecommons.org/licenses/by/4.0/). 